\title{
Rhizobacteria-mediated induced systemic resistance (ISR) in Arabidopsis requires sensitivity to jasmonate and ethylene but is not accompanied by an increase in their production
}

\author{
CORNÉ M. J. PIETERSE1*, JOHAN A. VAN PELT ${ }^{1}$, JURRIAAN TON ${ }^{1}$, STEFANIE \\ PARGHMANN ${ }^{2}$, MARTIN J. MUELLER ${ }^{2}$, ANTONY J. BUCHALA ${ }^{3}$, \\ JEAN-PIERRE MÉTRAUX ${ }^{3}$ and LEENDERT G. VAN LOON ${ }^{1}$
}

\begin{abstract}
${ }^{1}$ Graduate School Experimental Plant Sciences, Section of Phytopathology, Faculty of Biology, Utrecht University, P.O. Box 800.84, 3508 TB Utrecht, The Netherlands, ${ }^{2}$ Institute of Pharmaceutical Biology, Munich University, Butenandtstrasse 5, D-81377 Munich, Germany and ${ }^{3}$ Department of Biology, University of Fribourg, CH-1700 Fribourg, Switzerland
\end{abstract}

(Accepted for publication August 2000)

\begin{abstract}
Plants develop an enhanced defensive capacity against a broad spectrum of plant pathogens after colonization of the roots by selected strains of nonpathogenic biocontrol bacteria. In Arabidopsis thaliana, this induced systemic resistance (ISR) functions independently of salicylic acid but requires an intact response to the plant hormones jasmonic acid (JA) and ethylene. To further investigate the roles of JA and ethylene in the ISR signalling pathway, the levels of these signalling molecules were determined in A. thaliana upon induction of ISR by Pseudomonas fluorescens WCS417r and subsequent challenge inoculation with Pseudomonas syringae pv. tomato DC3000. Upon treatment of the roots with ISR-inducing WCS417r bacteria, neither the JA content, nor the level of ethylene evolution was altered in systemically resistant leaves. Infiltration of leaves with WCS417r triggered the JA- and ethylene-dependent ISR pathway, but did not cause local changes in the production of either of these signalling molecules. These results indicate that rhizobacteria-mediated ISR is not based on the induction of changes in the biosynthesis of either JA or ethylene. However, in ISR-expressing plants the capacity to convert 1-aminocyclopropane-1-carboxylate $(\mathrm{ACC})$ to ethylene was significantly enhanced, providing a greater potential to produce ethylene upon pathogen attack.

(C) 2000 Academic Press
\end{abstract}

Keywords: Arabidopsis thaliana; biological control; defense signalling; ethylene; induced systemic resistance (ISR); jasmonic acid; Pseudomonas fluorescens; Pseudomonas putida; Pseudomonas syringae pv. tomato; salicylic acid-independent; systemic acquired resistance (SAR).

\section{INTRODUCTION}

Rhizosphere bacteria are present in large numbers on root surfaces, where plant exudates and lysates provide nutrients [25]. Certain strains of rhizosphere bacteria stimulate plant growth and are therefore called plant growth-promoting rhizobacteria (PGPR). Strains that were isolated from naturally disease-suppressive soils, mainly fluorescent Pseudomonas spp., have been demonstrated to reduce plant diseases by suppressing soil-borne pathogens. This biological control activity is effective under field conditions $[48,58]$ and in commercial greenhouses [24], and can be the result of competition for nutrients, siderophore-mediated competition for iron, or antibiosis [1]. Some of these biological control strains are also able to reduce disease caused by foliar pathogens by triggering a plant-mediated resistance

\footnotetext{
* To whom all correspondence should be addressed. E-mail: c.m.j.pieterse@bio.uu.nl
}

mechanism called induced systemic resistance (ISR) [50]. Rhizobacteria-mediated ISR has been reported for bean, carnation, cucumber, radish, tobacco, tomato and the model plant Arabidopsis thaliana, and is effective against different types of plant pathogens. In this respect, ISR resembles pathogen-induced systemic acquired resistance (SAR), which renders uninfected plant parts more resistant towards a broad spectrum of pathogens $[40,44]$. Previously, we developed an Arabidopsis-based model system to study the molecular basis underlying rhizobacteria-mediated ISR [37]. Colonization of Arabidopsis roots by ISR-inducing Pseudomonas fluorescens WCS417r bacteria protects the plants against different types of pathogens, including the bacterial leaf pathogens Pseudomonas syringae pv. tomato and Xanthomonas campestris pv. armoraciae, the fungal root pathogen Fusarium oxysporum and the fungal leaf pathogen Peronospora parasitica [37, 53] (J. Ton and C. M. J. Pieterse, unpublished work). 
The ISR signalling pathway clearly differs from the one controlling pathogen-induced SAR. The state of SAR is characterized by an early increase in endogenously synthesized salicylic acid (SA) $[26,30]$ and the concomitant activation of a set of so-called SAR genes [56]. Many SAR genes encode pathogenesis-related proteins (PRs) [49], some of which have been shown to possess anti-fungal activity and are thought to contribute to induced resistance. Transgenic NahG plants that express the bacterial salicylate hydroxylase $(n a h G)$ gene and thus cannot accumulate SA, are incapable of developing SAR and do not show SAR gene activation upon pathogen infection, indicating that $\mathrm{SA}$ is a necessary intermediate in the SAR signalling pathway [14]. Some rhizobacteria trigger the SA-dependent SAR pathway by producing SA at the root surface [11-13, 28]. However, P. fluorescens WCS417r induces normal levels of protection against $P$. syringae pv. tomato DC3000 in NahG plants that do not accumulate SA, demonstrating that WCS417r-mediated ISR is SA-independent [37]. Instead, the WCS417r-mediated ISR pathway requires components from the jasmonic acid (JA) and the ethylene response, because the JA response mutant jar1-1 [39] and a range of ethylene response mutants are unable to express WCS417r-mediated ISR [21, 39]. Interestingly, the level of induced resistance can be enhanced further when ISR and SAR are activated simultaneously, indicating that ISR and SAR are additive [51].

Increased production of JA and ethylene is an early symptom of active defense in plants [7, 16, 27]. Blocking the response to either of these signal molecules renders plants more susceptible to pathogens [17, 22, 43, 46, 55] and even insects [29]. Both JA and ethylene co-ordinate the activation of a large set of defense responses, and when applied exogenously can induce resistance themselves [4, 6, 39]. In Arabidopsis, both JA and ethylene have been shown to activate specific sets of defense-related genes and resistance against $P$. syringae pv. tomato DC3000 [39, 52]. Recently, Van Wees et al. [52] monitored the expression of a set of well-characterized JA- and/or ethylene-responsive genes (i.e. Lox1, Lox2, Atvsp, Pdf1.2, $\mathrm{Hel}$, ChiB and Pal1) in Arabidopsis plants expressing WCS417r-mediated ISR. None of the genes tested were up-regulated in induced plants, neither locally in the roots, nor systemically in the leaves. This suggested that ISR is not accompanied by major changes in the production of either JA or ethylene, but rather seems to be the result of sensitization of the tissue to these regulators. This latter hypothesis is supported by our recent finding that the JA-inducible gene Atvsp shows a potentiated expression in ISR-expressing leaves after challenge with virulent $P$. syringae pv. tomato DC3000 [52]. In other plant systems similar phenomena have been reported. For instance, Schweizer et al. [41] demonstrated that during infection of rice with the fungal pathogen Magnaporthe grisea, jasmonate-inducible genes are activated without an increase in endogenous JA levels. Moreover, Tsai et al. [47] provided evidence that an increase in ethylene sensitivity rather than ethylene production is the initial event in triggering JA-enhanced senescence in detached rice leaves. These results demonstrate that ethylene- and JA-dependent plant responses can be triggered without a concomitant increase in the levels of these phytohormones.

Recently, Van Wees et al. [52] tested a concentration range of the resistance-inducing agents methyl jasmonate (MeJA) and the ethylene precursor 1-aminocyclopropane-1-carboxylate (ACG) for their effect on both the level of induced protection against $P$. syringae $\mathrm{pv}$. tomato DC3000 and the level of expression of JA-, and ethyleneresponsive marker genes. A maximal level of resistance was already achieved at five- to 100 -fold lower concentrations than needed for the induction of the expression of the marker genes. Thus, JA- or ethylene-dependent resistance can be elicited in the absence of detectable changes in JA- or ethylene-responsive gene expression. For this reason, it cannot be excluded that subtle changes in the production of either JA or ethylene may be sufficient to trigger the ISR pathway without directly activating the expression of the JA- and ethyleneresponsive genes.

To further investigate the role of JA and ethylene in the ISR signalling pathway, we tested whether the state of WCS417r-mediated ISR is associated with changes in the production of JA and/or ethylene. To this end, we monitored the local and systemic levels of these signalling molecules in ISR-expressing plants. Moreover, we tested transgenic Arabidopsis S-12 plants, that lack the lipoxygenase isozyme LOX2 required for wound-induced synthesis of JA, for their ability to express WCS417rmediated ISR against $P$. syringae pv. tomato DC3000 infection. Finally, we investigated whether ISR-expressing plants have a higher capacity to produce ethylene by determining ethylene evolution after application of the ethylene precursor ACC. Our results demonstrate that the JA and ethylene dependency of WCS417r-mediated ISR is not based on changes in the production of either JA or ethylene. However, Arabidopsis plants develop a higher ACG-converting capacity upon induction of ISR. The possible roles of JA and ethylene in the ISR pathway are discussed.

\section{MATERIALS AND METHODS}

\section{Bacterial cultures}

Nonpathogenic rhizobacterial strains $P$. fluorescens WCS417r, P. fluorescens WCS374r and P. putida WCS358r were grown on King's medium B agar plates 
[20] for $24 \mathrm{~h}$ at $28^{\circ} \mathrm{C}$. Subsequently, bacterial cells were collected and resuspended in $10 \mathrm{~mm} \mathrm{MgSO}_{4}$ to a final density of $10^{9} \mathrm{cfu} \mathrm{ml}^{-1}\left(\mathrm{OD}_{600}=1 \cdot 0\right)$ before being mixed through the soil. For leaf infiltration experiments, the rhizobacterial suspensions were diluted 100 -fold in $10 \mathrm{mM} \mathrm{MgSO}_{4}$ to a final density of $10^{7} \mathrm{cfu} \mathrm{ml}^{-1}$.

The avirulent pathogen $P$. syringae pv. tomato strain DC3000 with the plasmid pV288 carrying avirulence gene avrRt2 [23] was used for induction of SAR. P. syringae pv. tomato DC3000 (avrRpt2) bacteria were cultured overnight at $28^{\circ} \mathrm{C}$ in liquid King's medium B, supplemented with $25 \mathrm{mg} \mathrm{l}^{-1}$ kanamycin to select for the plasmid. Bacterial cells were collected by centrifugation and resuspended in $10 \mathrm{~mm} \mathrm{MgSO}_{4}$ to a final density of $10^{7} \mathrm{cfu} \mathrm{ml}^{-1}$.

The virulent pathogen $P$. syringae pv. tomato strain DC3000 [59], used for challenge inoculations, was grown overnight in liquid King's medium B at $28^{\circ} \mathrm{C}$. After centrifugation, the bacterial cells were resuspended in $10 \mathrm{mM} \mathrm{MgSO}_{4}$ containing $0.01 \%(\mathrm{v} / \mathrm{v})$ of the surfactant Silwet L-77 (Van Meeuwen Chemicals BV, Weesp, The Netherlands) to a final density of $2.5 \times 10^{7} \mathrm{cfu} \mathrm{ml}^{-1}$.

\section{Cultivation of plants}

Seeds of wild-type A. thaliana ecotype Col-0 plants, transgenic S-12 plants harbouring a sense construct of Lox2 cDNA behind the constitutive 35S-CaMV promoter [2], transgenic NahG plants harbouring the bacterial nah $G$ gene [10] and mutant jar1-1 [42], etr1-1 [3] and npr11 [5] plants were sown in quartz sand. Two week old seedlings were transferred to $60 \mathrm{ml}$ pots containing a sand-potting soil mixture that had been autoclaved twice for $20 \mathrm{~min}$ at $121^{\circ} \mathrm{C}$ with a $24 \mathrm{~h}$ interval. Before transfer of the seedlings, the potting soil was supplemented with either a suspension of rhizobacteria or an equal volume of a solution of $10 \mathrm{~mm} \mathrm{MgSO}$. Plants were cultivated in a growth chamber with a $9 \mathrm{~h}$ day $\left(200 \mu \mathrm{E} \mathrm{m}^{-2} \mathrm{~s}^{-1}\right.$ at $\left.24^{\circ} \mathrm{C}\right)$ and a $15 \mathrm{~h}$ night $\left(20^{\circ} \mathrm{C}\right)$ cycle at $70 \% \mathrm{RH}$. Plants were watered on alternate days and once a week supplied with a modified half-strength Hoagland's nutrient solution, as described [37].

\section{Induction treatments}

ISR-inducing and noninducing rhizobacteria were applied in either of the two ways: (1) plant roots were treated by transferring two-week-old seedlings to soil that was mixed with a suspension of rhizobacteria to a final density of $5 \times 10^{7} \mathrm{cfu} \mathrm{g}^{-1}$ of soil; or (2) three lower leaves of 5 week old plants were pressure infiltrated with a suspension of rhizobacteria at $10^{7} \mathrm{cfu} \mathrm{ml}^{-1}$ using a $1 \mathrm{ml}$ syringe without a needle. Pathogen-induced SAR was triggered in a similar manner by pressure infiltrating a suspension of the avirulent pathogen $P$. syringae pv. tomato
DC3000 (avrRpt2) at $10^{7} \mathrm{cfu} \mathrm{ml}^{-1}$ into three lower leaves of 5 week old plants. Of the control plants, three lower leaves were pressure infiltrated with $10 \mathrm{~mm} \mathrm{MgSO}_{4}$. In the figures, root treatments are indicated with the extension " $(\mathrm{R})$ ", whereas leaf treatments are indicated with the extension " $(\mathrm{L})$ ".

To relate ISR to levels of JA, SA and ethylene, nontreated leaves of treated plants were harvested. Just before harvest, the treated plant parts (either the root system or the pressure-infiltrated leaves) were removed. Subsequently, rosettes were either frozen in liquid nitrogen (for JA and SA extraction), or transferred to gas-tight serum flasks (for ethylene measurement).

For the determination of local production of JA and ethylene, all fully expanded leaves of 5 week old plants were pressure infiltrated with rhizobacteria, the avirulent pathogen $P$. syringae pv. tomato DC3000 (avrRpt2), or $10 \mathrm{mM} \mathrm{MgSO}_{4}$ as described above. At intervals, rosettes were detached from the root system and either frozen in liquid nitrogen (for JA extraction), or transferred to gastight vials (for ethylene measurement).

\section{Challenge inoculation and disease assessment}

Before challenge inoculation, root-treated plants were allowed to grow for 3 weeks in soil supplemented with rhizobacteria. Leaf-treated plants were challenged 3 days after pressure infiltration. One day before challenge, the plants were placed at $100 \% \mathrm{RH}$. Nonflowering plants were challenge inoculated by dipping the rosettes in a suspension of the virulent pathogen $P$. syringae pv. tomato DC3000 at $2.5 \times 10^{7} \mathrm{cfu} \mathrm{ml}^{-1}$ in $10 \mathrm{mM} \mathrm{MgSO}, 0.01 \%$ $(\mathrm{v} / \mathrm{v})$ Silwet L-77. Four days after challenge, disease severity was assessed by determining the percentage of leaves with symptoms per plant $(n=20)$. Leaves were scored as diseased when showing necrotic or water-soaked lesions surrounded by chlorosis. Pressure-infiltrated leaves were ignored during disease assessment.

\section{Extraction and quantification of $\mathcal{F A}$}

Leaves were frozen in liquid nitrogen and pulverized with mortar and pestle. One $g$ of fresh weight was used to extract JA. One hundred ng of 9,10-dihydrojasmonic acid were added per gram of fresh weight as an internal standard. Extraction and GC-MS quantification of JA was carried out as described by Mueller and Brodschelm [31].

\section{Ethylene measurement}

Individual rosettes were detached from the roots, weighed and placed in $25 \mathrm{ml}$ gas-tight serum flasks that were subsequently incubated under climate chamber conditions. At intervals, $1 \mathrm{ml}$ gas samples were withdrawn 
through the rubber seal. The concentration of ethylene was determined by GC as described by De Laat and Van Loon [9]. To determine the capacity of leaf tissue to convert ACG to ethylene, rosettes were dipped in a solution containing $1 \mathrm{~mm} \mathrm{ACG}$ and $0.01 \%(\mathrm{v} / \mathrm{v})$ Silwet L-77. Control plants were dipped in $0.01 \%(\mathrm{v} / \mathrm{v})$ Silwet L-77 only. Excess moisture was removed from the leaves with paper towels. The leaves were weighed, placed in $25 \mathrm{ml}$ gas-tight serum flasks, and ethylene production was measured as described above.

\section{Extraction and quantification of $S A$}

Leaves were frozen in liquid nitrogen and pulverized with mortar and pestle. For the analysis of free and conjugated SA, $200 \mathrm{ng}$ of the internal standard ortho-anisic acid was added per gram of fresh weight. Subsequently, extraction and quantification of free and conjugated SA were carried out as described by Meuwly and Métraux [32].

\section{RESULTS}

ISR is not associated with increased levels of $\mathcal{F A}$, ethylene or $S A$ in systemic tissues

To assess whether colonization of the roots with ISRinducing WCS417r bacteria is associated with systemic changes in JA or ethylene production, hormone levels were monitored in leaves of Arabidopsis ecotype Col-0 plants that were grown for 3 weeks in soil with or without WCS417r bacteria. Expression of ISR against virulent $P$. syringae pv. tomato DC3000 was verified in a subset of plants using our standard ISR bioassay [37] (data not shown). As a measure of induction by pathogenic bacteria, JA content and ethylene evolution were measured in leaves that were pressure infiltrated with the avirulent pathogen $P$. syringae pv. tomato DC3000 (avrRpt2). The production of both JA and ethylene was stimulated after infiltration of the leaves with avirulent bacteria as expected [Fig. 1(a) and (b)]. However, in noninfected leaves of ISR-expressing plants the JA level was similar to that observed in noninfected control plants. Also the production of ethylene was comparable in control and ISR-expressing plants. The latter confirms previous findings by Knoester et al. [21]. Thus, it can be concluded that induction of ISR through colonization of the rhizosphere with ISR-inducing WCS417r bacteria, does not result in an overall increase in the production of either JA or ethylene in the aerial plant parts.

WCS417r-mediated ISR functions independently of $\mathrm{SA}$ and is not associated with SA-inducible $P R$ gene activation [37]. Therefore it can be expected that WCS417r-mediated ISR is not associated with changes in SA levels. Indeed, ISR-expressing leaves showed no elevated levels of either free or conjugated SA [Fig. 1(c)], this in contrast to systemic tissue expressing pathogeninduced SAR. (a)

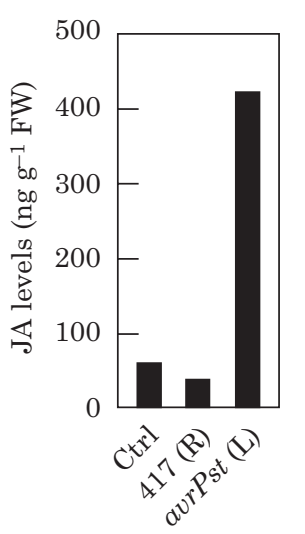

(b)

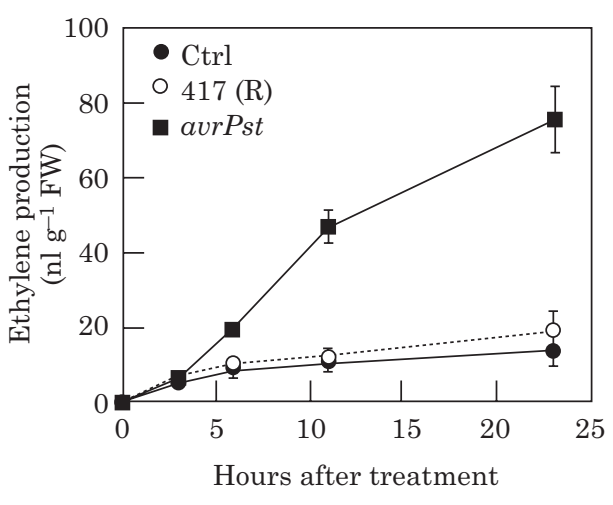

(c)

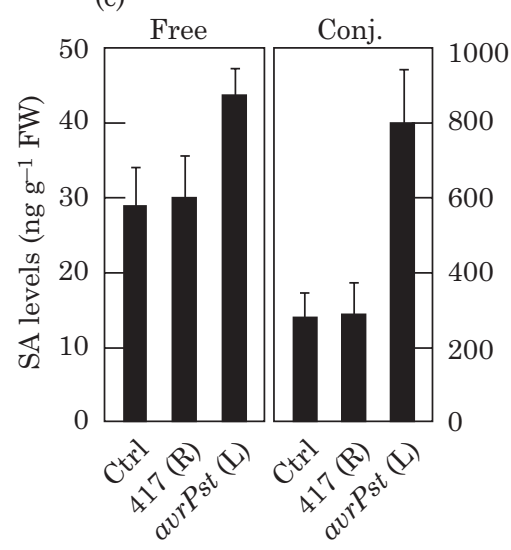

Fig. 1. Systemic production of JA, ethylene, and SA in Arabidopsis leaves expressing rhizobacteria-mediated ISR. (a) Endogenous JA levels in leaves of Col-0 plants that were grown in soil with [417 (R)] or without (Ctrl) ISR-inducing WCS417r bacteria, and in leaves inoculated with P. syringae pv. tomato DC3000 (avrRpt2) $24 \mathrm{~h}$ after pressure infiltration [avrPst (L)]. The values represented are from 10 pooled plants that received the same treatment. (b) Cumulative ethylene production over a 24 h time period in leaves of Col-0 plants that were grown in soil with or without ISR-inducing WCS417r bacteria, and in leaves inoculated with $P$. syringae pv. tomato DC3000 (avrRpt2). The represented values are means ( \pm S.E.) for 10 plants that received the same treatment. (c) Endogenous levels of free and conjugated SA in leaves of Col-0 plants that were grown in soil with or without ISR-inducing WCS417r bacteria, and in systemic leaf tissue expressing P. syringae pv. tomato DC3000 (avrRpt2)-induced SAR 3 days after induction of SAR. The values presented are means $( \pm$ S.E. $)$ for five plants that received the same treatment. FW, fresh weight. The experiments were repeated with similar results. 
Infiltration of leaves with ISR-inducing rhizobacteria triggers the ISR signalling pathway

Previously, we demonstrated that infiltration of leaves with ISR-inducing rhizobacteria induces protection against $P$. syringae pv. tomato DC3000 in noninfiltrated leaves [37]. Before we investigated whether elicitation of ISR through leaf infiltration is accompanied by local changes in the production of JA and/or ethylene, we first tested whether infiltration of leaves with ISR-inducing rhizobacteria triggers the same signalling pathway as root application. To this end, the Arabidopsis genotypes Col-0, NahG, jar1-1, etr1-1 and npr1-1 were tested for their ability to express ISR against $P$. syringae pv. tomato DC3000 after pressure infiltrating three lower leaves with ISR-inducing WCS417r bacteria. Three days after induction, upper leaves were challenge inoculated with virulent $P$. syringae pv. tomato DC3000 bacteria and plants were assessed for disease severity 4 days later. Fig. 2(a) shows that leaf infiltration and root application of WCS417 $r$ are similarly effective in eliciting ISR in wild-type Col-0 plants. SA-deficient NahG plants also developed a statistically significant level of ISR after leaf induction, although the magnitude of the effect was somewhat lower than in wild-type Col-0 plants. This can be explained by the fact that the highly susceptible NahG plants were more heavily diseased $(87.2 \%$ of the leaves of the control NahG plants showing symptoms vs. $61 \cdot 1 \%$ in wild-type Col-0 plants), which usually results in a lower efficacy of ISR induction (C.M.J. Pieterse, unpublished observations). Mutants jar1-1, etr1-1 and npr1-1 did not express ISR after infiltration of the leaves with ISR-inducing WCS417r bacteria. These results are in full agreement with the results of a previous study in which we tested the same Arabidopsis genotypes on their ability to express ISR against $P$. syringae pv. tomato DC3000 after application of WCS417r bacteria to the roots [39].

In Arabidopsis, rhizobacteria-mediated ISR depends on the rhizobacterial strain used. Previously, Van Wees et al. [53] demonstrated that treatment of the roots with strain WCS417r and P. putida WCS358r induces ISR against P. syringae pv. tomato DC3000, whereas strain P. fluorescens WCS374r is ineffective. Consistent with these findings, infiltration of three lower leaves per plant with WCS417r or WCS358r resulted in a significant level of protection against $P$. syringae pv. tomato DC3000 in the nontreated leaves, whereas WCS374r did not induce resistance [Fig. 2(b)]. Together, these results demonstrate that ISR-inducing rhizobacteria trigger the same systemic signalling pathway when applied to either roots or leaves.

Induction of ISR is not accompanied by local changes in the production of $\mathrm{JA}$

To determine endogenous JA levels at the site of ISR induction, leaves of Arabidopsis Col-0 plants were infiltrated with the ISR-inducing strains WCS417r or
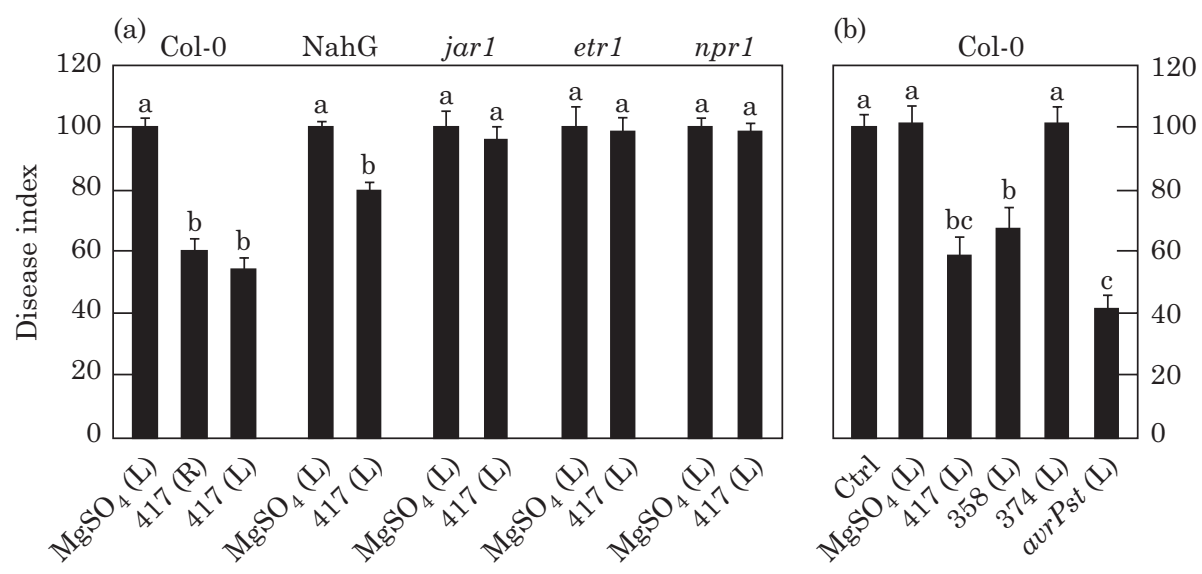

FIG. 2. Quantification of ISR against P. syringae pv. tomato DC3000 in Arabidopsis. In (a) ISR was induced in Arabidopsis genotypes Col-0, NahG, jar1-1, etr1-1 and npr1-1 by either growing the plants in soil containing ISR-inducing WCS417r bacteria [417 (R)], or by infiltrating three lower leaves per plant with WCS417r [417 (L)] 3 days before challenge inoculation. Three lower leaves per plant were pressure infiltrated with $10 \mathrm{mM} \mathrm{MgSO}_{4}\left[\mathrm{MgSO}_{4}(\mathrm{~L})\right]$ as a control. In (b) ISR was quantified in wild-type Col-0 plants after infiltration of three leaves per plant with the rhizobacterial strains WCS417r [417 (L)], WCS358r [358 (L)], WCS374r [374 $(\mathrm{L})]$, or $10 \mathrm{mM} \mathrm{MgSO}_{4}\left[\mathrm{MgSO}_{4}(\mathrm{~L})\right]$. The disease index is the mean $( \pm$ s.E., $n=20)$ of the percentage of leaves with symptoms per plants 4 days after challenge with virulent P. syringae pv. tomato DC3000, in comparison to control-treated plants (set at $100 \%$ ), The absolute proportions of diseased leaves of the control-treated plants were in (a) $61 \cdot 1 \%$ (Col-0), 87.2\% (NahG), 63.9\% (jar1-1), $58.6 \%($ etr $1-1)$ and $74.3 \%($ pr $1-1)$ and in (b) 58.0 \% (Ctrl). Within each frame, different letters indicate statistically significant differences between treatments (Fisher's LSD test, $\alpha=0 \cdot 05)$. The experiments were repeated with similar results. 
WCS358r, or with the noninducing strain WCS374r. Leaves were infiltrated with avirulent $P$. syringae pv. tomato DC3000 (avrRpt2) as a positive control. Fig. 3(a) shows that infiltration of the leaves with $P$. syringae pv. tomato DC3000 (avrRpt2) resulted in a strong increase in the JA content, which reached a maximum $24 \mathrm{~h}$ after infiltration. Upon infiltration with WCS417r bacteria, the JA content in the leaves remained at a low, basal level comparable to the JA content of noninfiltrated leaves. Infiltration of the leaves with the ISR inducer WCS358r or the noninducer WCS374r did not result in elevated JA levels either [Fig. 3(b)]. Evidently, induction of ISR is not accompanied by local changes in JA content of the leaves.

\section{Transgenic Arabidopsis S-12 plants express normal levels of ISR}

The enzyme lipoxygenase (LOX) plays an important role in the octadecanoid pathway leading to the biosynthesis of JA [54]. Transgenic Arabidopsis S-12 plants have severely reduced levels of the lipoxygenase isozyme LOX2 due to co-suppression of the Lox2 gene. The reduced LOX2 levels in S-12 plants have no effect on the steady-state JA level, but the wound-induced production of JA is blocked [2]. To verify whether S-12 plants are also impaired in pathogen-induced production of JA, JA levels were determined in water- and $P$. syringae pv. tomato DC3000-infiltrated leaves of Col-0 and S-12 plants. Two days after treatment, $P$. syringae pv. tomato DC3000infiltrated Col-0 leaves showed an eight-fold increase in
JA levels compared to the water control (115 vs. $15 \mathrm{ng} \mathrm{g}^{-1} \mathrm{FW}$, respectively). In contrast, water- and P. syringae pv. tomato DC3000-infiltrated S-12 leaves showed similar, low basal levels of JA (8 vs. $19 \mathrm{ng} \mathrm{g}^{-1}$ FW, respectively), indicating that S-12 plants are also blocked in pathogen-induced production of JA.

ISR induction is not accompanied by changes in JA content, therefore, S-12 plants are expected to express normal levels of ISR. To test this, wild-type Col-0 and transgenic S-12 plants were treated with ISR-inducing WCS417r bacteria, either by application to the roots, or by infiltration into the leaves. Both Col-0 and S-12 plants expressed a significant level of induced protection against P. syringae pv. tomato DC3000 after treatment of the roots with WCS417r (Fig. 4), indicating that a rise in JA content is not required for the expression of ISR. In S-12 plants, infiltration of three leaves per plant with WCS417r bacteria also resulted in a significant level of systemic resistance. This demonstrates that neither a local nor a systemic increase in JA content is required for expression of ISR.

In contrast to ISR, elicitation of SAR by pre-infecting three leaves per plant with $P$. syringae pv. tomato DC3000 (avrRpt2) results in a local [Fig. 1(a)] and a systemic (data not shown) increase in JA content. To investigate whether these increased JA levels play a role in the SAR pathway, we tested S-12 plants for their ability to express SAR. Like WCS417r-mediated ISR, SAR was not affected in S-12 plants (Fig. 4), indicating that increased JA levels are also not required for expression of SAR.
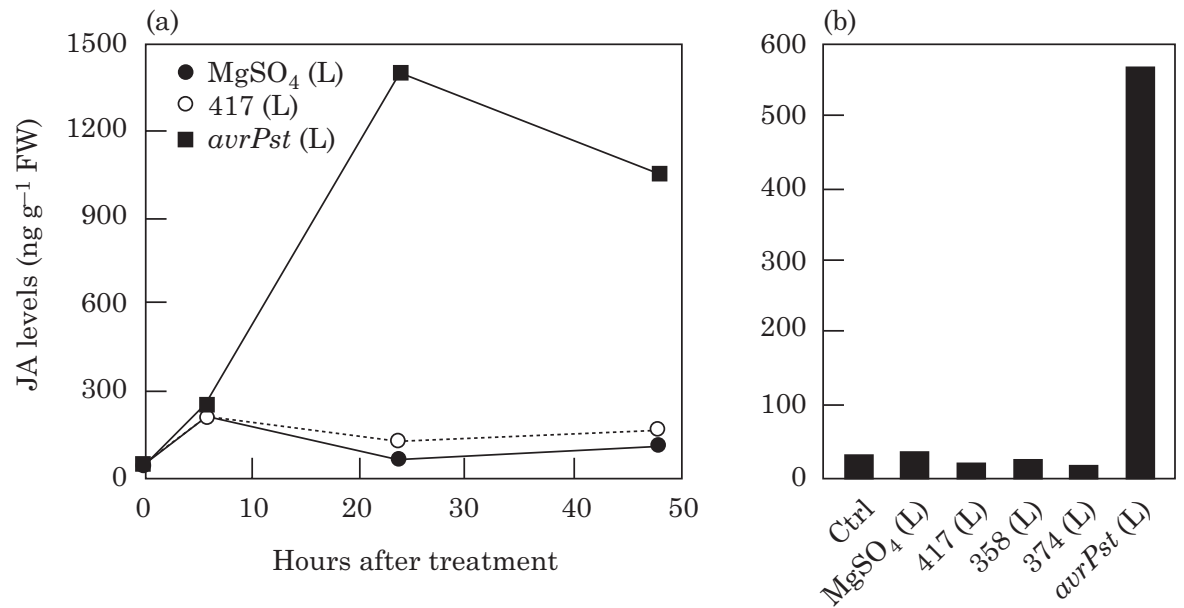

FIG. 3. Local accumulation of JA in Arabidopsis leaves after infiltration with rhizobacteria or P. syringae pv. tomato DC3000 (avrRpt2). (a) and (b) The values represent the endogenous JA content in leaves of Col-0 plants that were infiltrated with ISR-inducing WCS417r [417 (L)] or WCS358r bacteria [358 (L)], noninducing WCS374r bacteria [374 (L)], avirulent P. syringae pv. tomato DC3000 (avrRpt2) bacteria [avrPst (L)], or $10 \mathrm{~mm} \mathrm{MgSO}_{4}\left[\mathrm{MgSO}_{4}(\mathrm{~L})\right]$. The JA content was measured in noninfiltrated leaves as a control (Ctrl). In (a) leaves were collected 6, 24 and $48 \mathrm{~h}$ after infiltration, whereas in (b) leaves were harvested $24 \mathrm{~h}$ after infiltration. Data are from 10 pooled plants that received the same treatment. The experiments were repeated with similar results. 
Induction of ISR is not accompanied by local changes in ethylene production

Previously, Knoester et al. [21] demonstrated that rhizobacteria-mediated ISR in Arabidopsis requires ethylene perception at the site of application of the ISR inducing agent. To determine whether induction of ISR is accompanied by local changes in ethylene production at the site of application of the ISR inducer, ethylene evolution was monitored in leaves that were infiltrated with the ISR-inducing strains WCS417r or WCS358r, the noninducing strain WCS374r, or the SAR-inducing pathogen $P$. syringae pv. tomato DC3000 (avrRpt2). Infiltration with $P$. syringae pv. tomato DC3000 (avrRpt2) resulted in a substantial increase in ethylene production over the first $48 \mathrm{~h}$. In contrast, infiltration with WCS417r

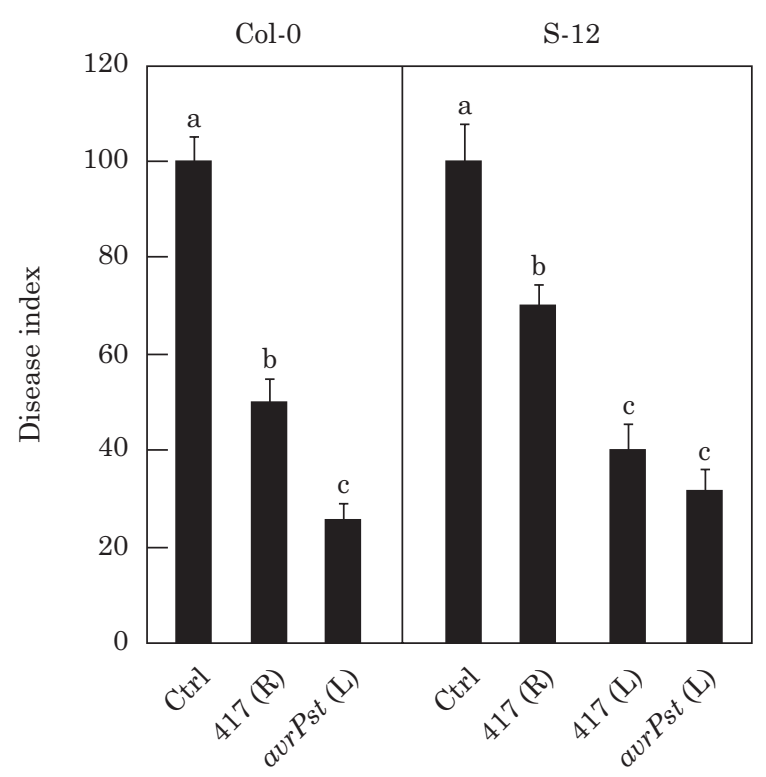

FIG. 4. Quantification of ISR and SAR against $P$. syringae pv. tomato DC3000 in Col-0 and S-12 plants. Induced protection against $P$. syringae pv. tomato DC3000 was quantified in wild-type Col-0 and in transgenic S-12 plants that are unable to produce elevated levels of JA. ISR was induced by either growing plants in soil containing ISR-inducing WCS417r bacteria [417 (R)], or by infiltrating three lower leaves per plant with WCS417r bacteria $[417(\mathrm{~L})] 3$ days before challenge inoculation with virulent $P$. syringae pv. tomato DC3000. SAR was induced by infiltrating three lower leaves per plant with the avirulent pathogen P. syringae pv. tomato DC3000 (avrRpt2) (avrPst) 3 days before challenge inoculation. The disease index is the mean $( \pm$ S.E., $n=20$ ) of the percentage of leaves with symptoms per plant 4 days after challenge with virulent $P$. syringae pv. tomato DC3000, in comparison to control-treated plants (set at $100 \%$ ). The absolute proportions of diseased leaves of the control-treated Col-0 and S-12 plants were 64.9 and $67.7 \%$, respectively. Within each frame, different letters indicate statistically significant differences between treatments (Fisher's LSD test, $\alpha=0 \cdot 05)$. The experiment was repeated with similar results. led to a slight increase in ethylene production in the first $24 \mathrm{~h}$ only. At later time points, ethylene production was comparable to that observed in $\mathrm{MgSO}_{4}$-infiltrated leaves. A similar small increase in ethylene production was observed in leaves that were infiltrated with either the ISR inducer WCS358r or the noninducer WCS374r [Fig. 5(b)], suggesting that this small increase in ethylene production is a nonspecific reaction of the leaf tissue to bacterial infiltration. It can thus be concluded that induction of ISR, through infiltration of leaves with ISRinducing rhizobacteria, is not accompanied by local changes in ethylene production. These results are in accord with previous findings of Knoester et al. [21], who demonstrated that induction of ISR by application of WCS417r to the roots is not associated with specific changes in the production of ethylene in the treated root tissue.

\section{ISR is associated with an enhanced capacity for converting $A C C$ to ethylene}

In higher plants, ethylene is produced from methionine via $S$-adenosyl-L-methionine and 1 -aminocyclopropane1 -carboxylate $(\mathrm{Met} \rightarrow \mathrm{SAM} \rightarrow \mathrm{ACC} \rightarrow$ ethylene $) \quad[18,19$, 45]. The last two steps of this biosynthetic pathway are catalysed by ACC synthase and ACC oxydase, respectively. Pathogen infections leading to chlorotic or necrotic symptoms cause an increase in ethylene production with ACG synthase and ACC oxidase activity being increased sequentially $[8]$. Whereas under normal conditions the conversion of SAM to ACG is the rate-limiting step, during infections ACG accumulates transiently, indicating that ACC oxidase activity restricts ethylene production. Previously, it was demonstrated that the capacity for converting ACG to ethylene was increased systemically in SAR-expressing tobacco and tomato plants [9], providing a greater capacity for producing ethylene after challenge inoculation. Fig. 6 shows that ethylene production in systemic tissues expressing either ISR or SAR was not raised compared to noninduced plants. To investigate whether WCS417r-mediated ISR in Arabidopsis is associated with an enhanced ACCconverting capacity in systemic tissue, ethylene production was measured in control and ISR-expressing plants after treatment of the leaves with a saturating dose of $1 \mathrm{~mm}$ ACC. The ACC-converting capacity in SAR-expressing plants was also examined as a check. Indeed, after application of $1 \mathrm{~mm}$ ACC, ISR-expressing plants showed a statistically significant higher level of ethylene production than ACG-treated control plants, irrespective of whether ISR was induced by WCS417rtreatment of the roots or by leaf infiltration. The magnitude of the increase in ACC-converting capacity varied from 20 to $50 \%$ between experiments and was comparable to that observed in SAR-expressing plants. 
(a)

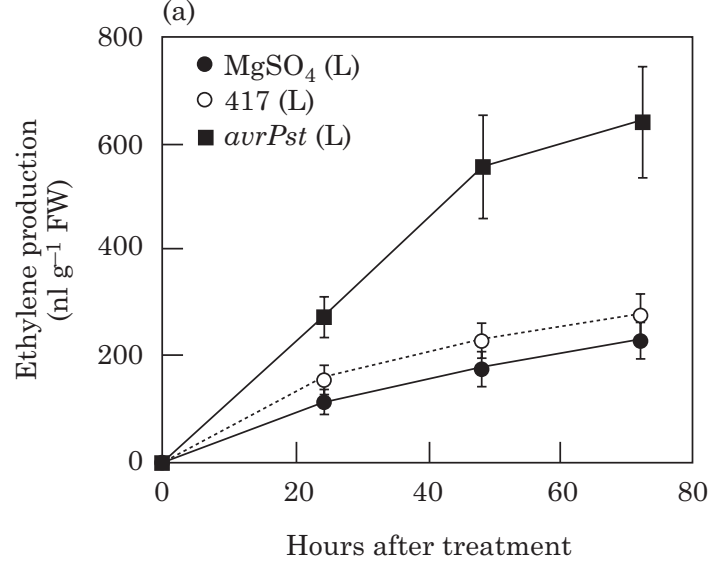

(b)

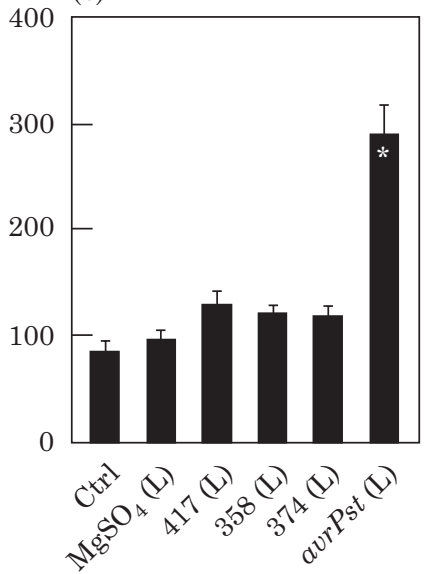

FIg. 5. Local ethylene production in Arabidopsis leaves after infiltration with rhizobacteria or P. syringae pv. tomato DC3000 (avrRpt2). (a) and (b) Cumulative ethylene production by leaves of Col-0 plants that were not treated (Ctrl) or infiltrated with either ISR-inducing WCS417r [417 (L)] or WCS358r bacteria [358(L)], noninducing WCS374r bacteria [374 (L)], avirulent P. syringae pv. tomato DC3000 (avrRpt2) bacteria [avrPst (L)], or $10 \mathrm{mM} \mathrm{MgSO}{ }_{4}\left[\mathrm{MgSO}_{4}(\mathrm{~L})\right]$. Ethylene production was determined

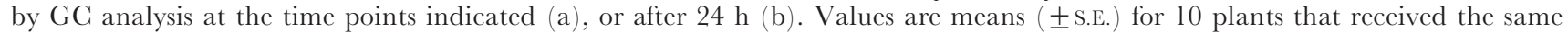
treatment. Asterisks indicated statistically significant differences compared to the control (Ctrl) treatment (Fisher's LSD test, $\alpha=0.05)$. The experiments were repeated with similar results. FW, fresh weight.

Evidently, the capacity to convert ACG to ethylene is increased in Arabidopsis plants expressing either ISR or SAR.

\section{DISCUSSION}

Recent advances in research on plant defense signalling pathways have shown that plants are capable of differentially activating distinct defense pathways depending on the type of invader encountered [36]. Upon pathogen infection, the production of JA and ethylene is stimulated, leading to the activation of specific defense-related genes [4, 57]. In Arabidopsis, increased biosynthesis of both JA and ethylene has been implicated in the pathogen-induced expression of the plant defensin gene Pdf1.2 [35] and in disease resistance signalling in response to the soft-rot pathogen Erwinia carotovora subsp. carotovora [34]. Like WCS417r-mediated ISR, both plant responses are SA-independent and require components from the JA and the ethylene response. To investigate whether ISR is associated with changes in JA and/or ethylene biosynthesis, we monitored local and systemic production of both signal molecules in plants expressing ISR. When plants were grown in soil containing ISR-inducing rhizobacteria, the JA content and the level of ethylene evolution in systemically resistant leaves was similar to that observed in noninduced control plants (Fig. 1). Moreover, infiltration of leaves with ISR-inducing rhizobacteria elicited JA- and ethylene-dependent resistance against $P$. syringae pv. tomato DC3000 (Fig. 2), but this was not accompanied by a local increase in the production of these hormones (Figs 3 and 5). It can thus be concluded that neither induction, nor expression of WCS417r-mediated ISR is associated with an increase in the production of either JA or ethylene. This conclusion fits with earlier observations that ISR is not accompanied by the activation of JA- or ethylene-inducible genes [39, 52].

By using the Lox2 co-suppressed transgenic line S-12, we confirmed that an increase in JA production is not required for the induction or expression of ISR. Transgenic S-12 plants, that are affected in the production of JA in response to wounding [2], expressed normal levels of ISR, irrespective of whether ISR was induced via roots or leaves (Fig. 4). This raises the question: how can the JAdependency of ISR be explained? A plausible explanation is that ISR-expressing plants are potentiated for the expression of JA-inducible, defense-related genes, leading to a faster and greater gene activation after infection with a challenging pathogen. Potentiation of defense-related gene activation has been demonstrated for SA-inducible $P R$ genes in SAR-expressing tobacco [33] and Arabidopsis plants [52]. Recently, we demonstrated that the expression of the JA-inducible Atvsp gene is potentiated in ISRexpressing plants [52], leading to a higher Atvsp transcript accumulation after challenge inoculation. However, other JA-inducible genes, i.e. Pdf1.2, Lox2 and Pal1, were not potentiated. Thus, the enhanced expression of Atusp cannot be explained by accelerated JA production during infection. Indeed, JA production after infection with P. syringae pv. tomato DC3000 does not increase faster in 


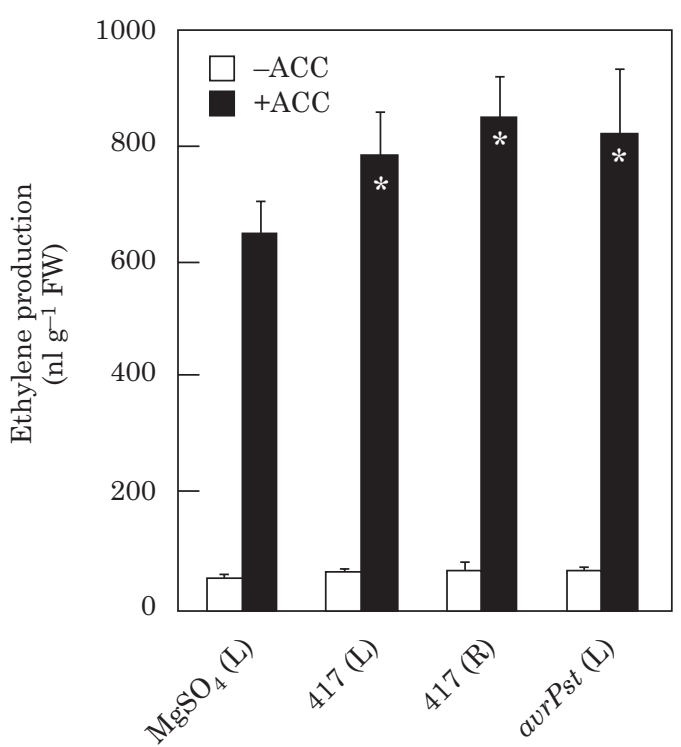

FIG. 6. ACG-converting capacity of ISR- and SAR-expressing plants. Ethylene produced over a $24 \mathrm{~h}$ period by leaves from noninduced plants and plants expressing either ISR or SAR. WCS417r-mediated ISR and P. syringae pv. tomato DC3000 (avrRpt2)-induced SAR were triggered as described in the text and legend to Fig. 4. Three days after infiltration of the leaves with either $10 \mathrm{mM} \mathrm{MgSO}_{4}$, WCS417r or P. syringae pv. tomato DC3000 (avrRpt2), the infiltrated leaves were removed and the remaining leaves were treated with $1 \mathrm{~mm}$ ACG. The ACGconverting capacity was determined by measuring the ethylene production in the $24 \mathrm{~h}$ period subsequent to the treatment with ACC. Values are means $( \pm$ s.E.) for 10 plants that received the same treatment. Asterisks indicate statistically significant differences compared to the control $\left(\mathrm{MgSO}_{4}\right)$ treatment (Fisher's LSD test, $\alpha=0 \cdot 05$ ). The experiment was repeated with similar results. FW, fresh weight.

ISR-expressing plants compared to infected control plants (data not shown). Therefore, potentiation of Atvsp gene expression must be the result of sensitization of the tissue for specific JA-responsive genes.

Similarly, WCS417r-mediated ISR is not accompanied by increased ethylene evolution. So how can the ethylene dependency of ISR then be explained? Previously, Knoester et al. [21] demonstrated that ethylene sensitivity is required at the site of ISR induction. Mutant eir1-1, which is insensitive to ethylene in the roots only, was able to mount ISR against $P$. syringae pv. tomato DC3000 when WCS417 $r$ was infiltrated in the leaves, but not when these bacteria were applied to the roots. This suggests that ethylene is involved in the generation or translocation of the systemically transported ISR signal. However, this does not rule out the possibility that ethylene responsiveness is required for the expression of ISR in tissues distant from the site of induction.

Previously, De Laat and Van Loon [9] demonstrated that the capacity for converting ACG to ethylene was increased systemically in tobacco leaves expressing tobacco mosaic virus-induced SAR. The authors postulated that this increase in ACG-converting capacity might be involved in limiting pathogen growth in systemically resistant leaves, because upon challenge inoculation ACG did not accumulate, but was converted faster to ethylene. In Arabidopsis, both WCS417r-mediated ISR and pathogen-induced SAR are associated with a significant enhancement of the ACC-converting capacity, indicative of increased AGG oxidase activity. In Arabidopsis, ACG oxidase is encoded by a single gene [15] whose expression is not enhanced in ISR- or SAR-expressing leaves [21] (C. M. J. Pieterse, unpublished results). Thus, the increase in ACG oxidase activity in systemically resistant leaves is likely to be regulated post-translationally. The enhanced capacity for converting ACG to ethylene provides a greater potential for producing ethylene upon pathogen attack. With the application of ACG being shown to induce resistance against $P$. syringae pv. tomato DC3000 in Arabidopsis [39], a faster or greater production of ethylene in the initial phase of infection might contribute to enhanced resistance against this pathogen. However, the significance of this phenomenon needs further investigation.

Fig. 7 combines these results in a model aimed at explaining the role of JA and ethylene in ISR signalling. In summary, ISR is a JA- and ethylene-dependent resistance response [39]. Ethylene responsiveness is required at the site of ISR induction, suggesting that this signal molecule is involved in the generation or translocation of the systemically transported signal [21]. ISR is neither locally, nor systemically accompanied by an increase in JA or ethylene biosynthesis (this study). In agreement with this, Arabidopsis plants show no increase in JA- or ethylene-responsive gene expression in response to induction of ISR $[39,52]$. ISR expressing plants have a higher capacity to convert ACG to ethylene, providing a greater potential to produce ethylene upon infection (this study). A specific set of JA-responsive genes is potentiated in ISR-expressing plants, leading to a higher level of expression after pathogen infection. For ethylene-responsive genes, such a potentiating effect was not observed [52]. Future research will be focussed on the mechanisms involved in the potentiation of JA-responsive gene expression and the increased ACG-converting capacity in relation to the level of induced resistance.

Drs Erin Bell, John Ryals, Paul Staswick and Xinnian Dong are acknowledged for kindly providing seeds of the Arabidopsis genotypes S-12, NahG, jar1-1 and npr1-1, respectively, the Nottingham Arabidopsis Stock Centre for providing etr $1-1$ seeds, and Dr Andrew Bent for providing P. syringae pv. tomato DC3000 strains. Part of this work was financed by a Swiss National Science Foundation grant (no. 3100.055.662.98) to J.P.M. 


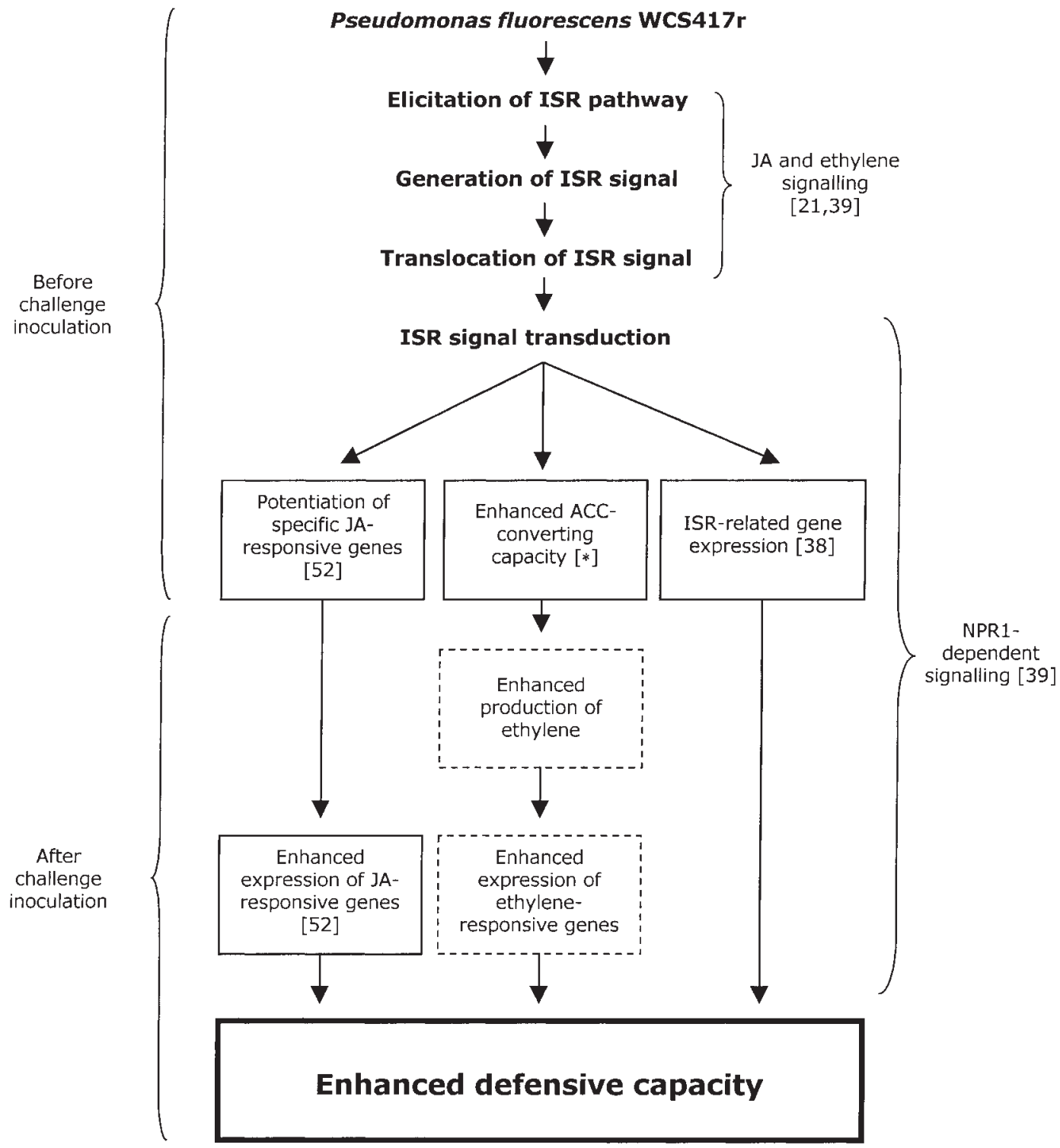

FIG. 7. Working model for the involvement of JA and ethylene in the Arabidopsis ISR signalling pathway. Hypothetical steps are in boxes with dotted lines. References are between square brackets. Asterisks indicate experimental evidence presented in this paper.

\section{REFERENCES}

1. Bakker PAHM, Van Peer R, Schippers B. 1991. Suppression of soil-borne plant pathogens by fluorescent Pseudomonads: mechanisms and prospects. In: Beemster ABR et al., eds. Biotic Interactions and Soil-Borne Diseases. Amsterdam: Elsevier Scientific Publishers, 217-230.

2. Bell E, Greelman RA, Mullet JE. 1995. A chloroplast lipoxygenase is required for wound-induced jasmonic acid accumulation in Arabidopsis. Proceedings of the National Academy of Sciences, USA 92: 8675-8679.

3. Bleecker AB, Estelle MA, Sommerville G, Kende H. 1988. Insensitivity to ethylene conferred by a dominant mutation in Arabidopsis thaliana. Science 241: 1086-1089.

4. Boller T. 1991. Ethylene in pathogenesis and disease resistance. In: Mattoo $\mathrm{AK}$, Suttle JC, eds. The Plant
Hormone Ethylene. Boca Raton, U.S.A.: CRS Press, 293-314.

5. Gao H, Bowling SA, Gordon AS, Dong X. 1994. Characterization of an Arabidopsis mutant that is nonresponsive to inducers of systemic acquired resistance. The Plant Cell 6: 1583-1592.

6. Gohen Y, Gisi U, Niderman T. 1993. Local and systemic protection against Phytophthora infestans induced in potato and tomato plants by jasmonic acid and jasmonic methyl ester. Phytopathology 83: 1054-1062.

7. De Laat AMM, Van Loon LC. 1981. Regulation of ethylene biosynthesis in virus-infected tobacco leaves. I Determination of the role of methionine as a precursor of ethylene. Plant Physiology 68: 256-260.

8. De Laat AMM, Van Loon LG. 1982. Regulation of ethylene biosynthesis in virus-infected tobacco leaves. II 
Time course of levels of intermediates and in vivo conversion rates. Plant Physiology 69: 240-245.

9. De Laat AMM, Van Loon LG. 1983. The relationship between stimulated ethylene production and symptom expression in virus-infected tobacco leaves. Physiological Plant Pathology 22: 261-273.

10. Delaney TP, Uknes S, Vernooij B, Friedrich L, Weymann K, Negrotto D, Gaffney T, Gur-Rella M, Kessmann H, Ward E, Ryals J. 1994. A central role of salicylic acid in plant disease resistance. Science 266: 1247-1250.

11. De Meyer G, Audenaert K, Höfte M. 1999a. Pseudomonas aeruginosa $7 \mathrm{NSK} 2$-induced systemic resistance in tobacco depends on in planta salicylic acid accumulation but is not associated with PR la expression. European Fournal of Plant Pathology 105: 513-517.

12. De Meyer G, Gapieau K, Audenaert K, Buchala A, Métraux J-P, Höfte M. 1999b. Nanogram amounts of salicylic acid produced by the rhizobacterium Pseudomonas aeruginosa 7NSK2 activate the systemic acquired resistance pathway in bean. Molecular Plant-Microbe Interactions 12: $450-458$.

13. De Meyer G, Höfte M. 1997. Salicylic acid produced by the rhizobacterium Pseudomonas aeruginosa 7NSK2 induces resistance to leaf infection by Botrytis cinerea on bean. Phytopathology 87: 588-593.

14. Gaffney T, Friedrich L, Vernooij B, Negrotto D, Nye G, Uknes S, Ward E, Kessmann H, Ryals J. 1993. Requirement of salicylic acid for the induction of systemic acquired resistance. Science 261: 754-756.

15. Gómez-Lim MA, Valdés-López V, Gruz-Hernandez A, Saucedo-Arias LJ. 1993. Isolation and characterization of a gene involved in ethylene biosynthesis from Arabidopsis thaliana. Gene 134: 217-221.

16. Gundlach H, Mueller MJ, Kutchan TM, Zenk MH. 1992. Jasmonic acid is a signal transducer in elicitorinduced plant cell cultures. Proceedings of the National Academy of Sciences, USA 89: 2389-2393.

17. Hoffman T, Schmidt JS, Zheng X, Bent AF. 1999. Isolation of ethylene-insensitive soybean mutants that are altered in pathogen susceptibility and gene-for-gene disease resistance. Plant Physiology 199: 935-949.

18. Kende H. 1993. Ethylene biosynthesis. Annual Review of Plant Physiology and Plant Molecular Biology 44: 283-307.

19. Kende H, Zeevaart JAD. 1997. The five 'classical' plant hormones. The Plant Cell 9: 1197-1210.

20. King EO, Ward MK, Raney DE. 1954. Two simple media for the demonstration of phycocyanin and fluorescin. Fournal of Laboratory and Clinical Medicine 44: 301-307.

21. Knoester M, Pieterse GMJ, Bol JF, Van Loon LG. 1999. Systemic resistance in Arabidopsis induced by rhizobacteria requires ethylene-dependent signaling at the site of application. Molecular Plant-Microbe Interactions 12: 720-727.

22. Knoester M, Van Loon LG, Van den Heuvel J, Hennig J, Bol JF, Linthorst HJM. 1998. Ethylene-insensitive tobacco lacks non-host resistance against soil-borne fungi. Proceedings of the National Academy of Sciences, USA 95: 1933-1937.

23. Kunkel BN, Bent AF, Dahlbeck D, Innes RW, Staskawicz BJ. 1993. RPS2, an Arabidopsis disease resistance locus specifying recognition of Pseudomonas syringae strains expressing the avirulence gene avrRpt2. The Plant Cell 5: 865-875.

24. Leeman M, Van Pelt JA, Hendrickx MJ, Scheffer RJ, Bakker PAHM, Schippers B. 1995. Biocontrol of fusarium wilt of radish in commercial greenhouse trials by seed treatment with Pseudomonas fluorescens WCS374r. Phytopathology 85: 1301-1305.

25. Lynch JM, Whipps JM. 1991. Substrate flow in the rhizosphere. In: Keister DL, Cregan PB, eds. The Rhizosphere and Plant Growth. Dordrecht: Kluwer, 15-24.

26. Malamy J, Carr JP, Klessig DF, Raskin I. 1990. Salicylic acid: a likely endogenous signal in the resistance response of tobacco to viral infection. Science 250: 1002-1004.

27. Mauch F, Hadwiger LA, Boller T. 1994. Ethylene: symptom, not signal for the induction of chitinase and $\beta$-1,3-glucanase in pea pods by pathogens and elicitors. Plant Physiology 76: 607-611.

28. Maurhofer M, Reimmann G, Schmidli-Sacherer P, Heeb S, Haas D, Défago G. 1998. Salicylic acid biosynthetic genes expressed in Pseudomonas fluorescens strain P3 improve the induction of systemic resistance in tobacco against tobacco necrosis virus. Phytopathology 88: 678-684.

29. McConn M, Greelman RA, Bell E, Mullet JE, Browse J. 1997. Jasmonate is essential for insect defense in Arabidopsis. Proceedings of the National Academy of Sciences, USA 94: 5473-5477.

30. Métraux J-P, Signer H, Ryals J, Ward E, Wyss-Benz M, Gaudin J, Raschdorf K, Schmid E, Blum W, Inverardi B. 1990. Increase in salicylic acid at the onset of systemic acquired resistance in cucumber. Science 250: 1004-1006.

31. Mueller MJ, Brodschelm W. 1994. Quantification of jasmonic acid by capillary gas chromatography-negative chemical ionization-mass spectrometry. Analytical Biochemistry 218: 425-435.

32. Meuwly P, Métraux J-P. 1993. Ortho-ansinic acid as internal standard for the simultaneous quantification of salicylic acid and its putative biosynthetic precursors in cucumber leaves. Analytical Biochemistry 214: 500-505.

33. Mur LAJ, Naylor G, Warner SAJ, Sugars JM, White RF, Draper J. 1996. Salicylic acid potentiates defence gene expression in tissue expressing acquired resistance to pathogen attack. The Plant fournal 9: 559-571.

34. Norman-Setterblad G, Vidal S, Palva ET. 2000. Interacting signal pathways control defense gene expression in Arabidopsis in response to cell wall-degrading enzymes from Erwinia carotovora. Molecular Plant-Microbe Interactions 13: 430-438.

35. Penninckx IAMA, Eggermont K, Terras FRG, Thomma BPHJ, De Samblanx GW, Buchala A, Métraux J-P, Manners JM, Broekaert WF. 1996. Pathogen-induced systemic activation of a plant defensin gene in Arabidopsis follows a salicylic acid-independent pathway. The Plant Cell 8: 2309-2323.

36. Pieterse GMJ, Van Loon LG. 1999. Salicylic acidindependent plant defence pathways. Trends in Plant Science 4: 52-58.

37. Pieterse GMJ, Van Wees SGM, Hoffland E, Van Pelt JA, Van Loon LC. 1996. Systemic resistance in Arabidopsis induced by biocontrol bacteria is independent of salicylic acid and pathogenesis-related gene expression. The Plant Cell 8: 1255-1237.

38. Pieterse GMJ, Van Wees SGM, Ton J, LéonKloosterziel KM, Van Pelt JA, Keurentjes JJB, Knoester M, Van Loon LG. 2000. Rhizobacteriamediated induced systemic resistance (ISR) in Arabidopsis: involvement of jasmonate and ethylene. In: De Wit PJGM, Bisseling T, Stiekema WJ, eds. Biology of Plant-Microbe Interactions, Vol. 2. St. Paul: International 
Society for Molecular Plant-Microbe Interactions, 291-296.

39. Pieterse GMJ, Van Wees SCM, Van Pelt JA, Knoester M, Laan R, Gerrits H, Weisbeek PJ, Van Loon LC. 1998. A novel signaling pathway controlling induced systemic resistance in Arabidopsis. The Plant Cell 10: 1571-1580.

40. Ryals JA, Neuenschwander UH, Willits MG, Molina A, Steiner H-Y, Hunt MD. 1996. Systemic acquired resistance. The Plant Cell 8: 1809-1819.

41. Schweizer P, Buchala A, Silverman P, Seskar M, Raskin I, Métraux J-P. 1997. Jasmonate-inducible genes are activated in rice by pathogen attack without a concomitant increase in endogenous jasmonic acid levels. Plant Physiology 114: 79-88.

42. Staswick PE, Su W, Howell SH. 1992. Methyl jasmonate inhibition of root growth and induction of a leaf protein are decreased in an Arabidopsis thaliana mutant. Proceedings of the National Academy of Sciences, USA 89: 6837-6840.

43. Staswick PE, Yuen GY, Lehman GG. 1998. Jasmonate signaling mutants of Arabidopsis are susceptible to the soil fungus Pythium irregulare. The Plant Fournal 15: 747-754.

44. Sticher L, Mauch-Mani B, Métraux J-P. 1997. Systemic acquired resistance. Annual Review of Phytopathology 35: 235-270.

45. Theologis A. 1992. One rotten apple spoils the whole bushel: the role of ethylene in fruit ripening. Cell 70: 181-184.

46. Thomma PHJ, Eggermont K, Penninckx IAMA, Mauch-Mani B, Vogelsang R, Cammue BPA, Broekaert WF. 1998. Separate jasmonate-dependent and salicylate-dependent defense-response pathways in Arabidopsis are essential for resistance to distinct microbial pathogens. Proceedings of the National Academy of Sciences, USA 95: 15107-15111.

47. Tsai F-Y, Hung KT, Kao GH. 1996. An increase in ethylene sensitivity is associated with jasmonate-promoted senescence of detached rice leaves. Fournal of Plant Growth Regulators 15: 197-200.

48. Tuzun S, Kloepper J. 1995. Practical application and implementation of induced resistance. In: Hammerschmidt R, Kuć J, eds. Induced Resistance to Diseases in Plants. Dordrecht: Kluwer Academic Press, $152-168$.
49. Van Loon LC. 1997. Induced resistance in plants and the role of pathogenesis-related proteins. European fournal of Plant Pathology 103: 743-765.

50. Van Loon LC, Bakker PAHM, Pieterse GMJ. 1998. Systemic resistance induced by rhizosphere bacteria. Annual Review of Phytopathology 36: 453-483.

51. Van Wees SGM, De Swart EAM, Van Pelt JA, Van Loon LG, Pieterse GMJ. 2000. Enhancement of induced disease resistance by simultaneous activation of salicylate- and jasmonate-dependent defense pathways in Arabidopsis thaliana. Proceedings of the National Academy of Sciences, USA 97: 8711-8716.

52. Van Wees SGM, Luijendijk M, Smoorenburg I, Van Loon LG, Pieterse GMJ. 1999. Rhizobacteriamediated induced systemic resistance (ISR) in Arabidopsis is not associated with a direct effect on known defensegenes but stimulates the expression of the jasmonateinducible gene Atvsp upon challenge. Plant Molecular Biology 41: 537-549.

53. Van Wees SGM, Pieterse GMJ, Trijssenaar A, Van 't Westende YAM, Hartog F, Van Loon LG. 1997. Differential induction of systemic resistance in Arabidopsis by biocontrol bacteria. Molecular Plant-Microbe Interactions 6: 716-724.

54. Vick BA, Zimmerman DC. 1984. Biosynthesis of jasmonic acid by several plant species. Plant Physiology 75: 458-461.

55. Vijayan P, Shockey J, Lévesque CA, Cook RJ, Browse J. 1998. A role for jasmonate in pathogen defense of Arabidopsis. Proceedings of the National Academy of Sciences, USA 95: 7209-7214.

56. Ward ER, Uknes SJ, Williams SG, Dincher SS, Wiederhold DL, Alexander DC, Ahl-Goy P, Métraux J-P, Ryals JA. 1991. Co-ordinate gene activity in response to agents that induce systemic acquired resistance. The Plant Cell 3: 1085-1094.

57. Wasternack G, Parthier B. 1997. Jasmonate-signalled plant gene expression. Trends in Plant Science 2: 302-307.

58. Wei G, Kloepper JW, Tuzun S. 1996. Induced systemic resistance to cucumber diseases and increased plant growth by plant growth-promoting rhizobacteria under field conditions. Phytopathology 86: 221-224.

59. Whalen MC, Innes RW, Bent AF, Staskawicz BJ. 1991. Identification of Pseudomonas syringae pathogens of Arabidopsis and a bacterial locus determining avirulence on both Arabidopsis and soybean. The Plant Cell 3: 49-59. 